\title{
Erratum to: Ultrasound-guided joint injections for MR arthrography in pediatric patients: how we do it
}

\author{
Jeffrey Otjen ${ }^{1} \cdot$ Shawn E. Parnell ${ }^{1} \cdot$ Sarah Menashe ${ }^{1}$. \\ Mahesh M. Thapa ${ }^{1}$
}

Published online: 2 June 2015

(C) Springer-Verlag Berlin Heidelberg 2015

\section{Erratum to: Pediatr Radiol}

\section{DOI 10.1007/s00247-014-3212-9}

A formatting error occurred in the production of Table 1 Sumary of ultrasound guided joint injection techniques. As a result, incorrect information is given for the line "Volume estimate." The correct entry should read as follows:

\begin{tabular}{cllllll}
\hline & Shoulder & Elbow & Hip & Knee & Ankle & Subtalar \\
$\begin{array}{c}\text { Volume } \\
\text { estimate* }\end{array}$ & $15-20$ cc & $3-7$ cc & $15-20$ cc & $30-40$ cc & $3-7$ cc & $3-7$ cc \\
\hline
\end{tabular}

*Volume varies from patient to patient and with age and size. This estimate reflects an average adolescent volume to generate adequate joint capsule distention 